\title{
UNDERSTANDING CULTURAL DETERMINANTS OF MOOCs OFFERING: A CROSS-COUNTRY STUDY
}

\author{
Dr. Fernanda Francielle de Oliveira MALAQUIAS \\ ORCID: 0000-0001-7997-530X \\ Faculdade de Gestao e Negocios \\ Universidade Federal de Uberlandia \\ Uberlandia, BRAZIL \\ Romes Jorge da Silva JUNIOR \\ ORCID: 0000-0003-1560-9794 \\ Faculdade de Gestao e Negocios \\ Universidade Federal de Uberlandia \\ Uberlandia, BRAZIL
}

Received: 16/09/2019 Accepted: 10/02/2020

\begin{abstract}
Massive Open Online Courses, also known as MOOCs, figure as the main trend in the international educational market in recent years, characterized by the offer of free, open access and global courses. Although many current studies address issues like design, quality and acceptance of these courses, little attention has been given regarding cultural aspects that could influence this global open learning movement. Therefore, the aim of this paper is to investigate cultural determinants of MOOCs offering, through a crosscountry analysis. To this end, four cultural factors proposed by Hofstede were considered. Through the multivariate regression analysis, we evaluated the relation between these factors and the number of MOOCs offered in each country. The results show that Individualism presents a significant and positive effect on MOOCs offering. Power Distance, Uncertainty Avoidance and Masculinity dimensions of culture do not present significant effect on MOOCs offering. This means that although individuals from countries with higher rates of Masculinity and lower levels of Uncertainty Avoidance and Power Distance are more likely to attend online courses, universities in these countries are not necessarily the ones offering more MOOCs. The results of the study may be useful to support the implementation of strategies for the diffusion and internationalization of MOOCs.
\end{abstract}

Keywords: MOOCs, e-learning, culture, distance education, global courses.

\section{INTRODUCTION}

In recent years, the paradigm of distance education has changed with the emergence of global open online courses known as MOOCs (Massive Open Online Courses) (Joo, So \& Kim, 2018). These courses are part of an open learning movement led by prestigious universities around the world that might be interpreted as a way of democratizing education by the offering of more affordable and accessible learning tools (Joo, So \& Kim, 2018).

Generally, MOOCs are offered completely online and are not taken in real time, which provides the students with considerable flexibility in terms of time and space (Freitas, Morgan \& Gibson, 2015; Pasha et al., 2016). In most cases, the courses are free of charge or require small fees for the possibility of receiving a certificate (Joo, So \& Kim, 2018). Additionally, the courses usually do not require enrollment fees, contributing even more to their popularity (Pasha, Abidi \& Ali, 2016).

Due to these characteristics, the MOOC phenomenon has been a common subject in recent studies that address issues like the impact of MOOCs on high education, quality assurance, accreditation, learning assessment, the concept of openness, among other topics (Jacoby, 2014). Several authors have also been focusing on better understand MOOCs users and their behavioral patterns (Alraimi, Zo \& Ciganek, 2015; Joo; So \& Kim, 2018; Albelbisi \& Yusop, 2019; Lu, Wang \& Lu, 2019). 
MOOCs represent both opportunities and challenges for educators. The courses have the potential to eliminate barriers in the learning process, as consequence of their openness in terms of enrolment, content, design, participation and assessment methods (Zawacki-Richter et al., 2018). However, Sanchez-Gordon and Lujan-Mora (2018) point out that although these courses play a relevant role for the achievement of universal education, their platforms and content are not sufficiently accessible to all students. Another challenge pointed by Despujol, Cataneda and Turro (2018) is how to make this courses self-sustained, especially in a context of economic crisis.

High dropout rates and variations in levels of engagement and motivations among users are also problems that need to be addressed (Park, Jung \& Reeves, 2015; Conole, 2015; Littlejohn et al., 2016; Albelbisi \& Yusop, 2019). In this sense, Fini (2009) states that in order to better evaluate the effectiveness of MOOCS, it is necessary to further research about the students' profiles, since these aspects can be related to course outcomes and retention.

As pointed by Park, Jung and Reeves (2015, p. 73), "MOOC learners come from different cultures, are of all ages and educational backgrounds and have different motivations". Bozkurt, Yazici and Aydin (2018) emphasize that the cultural diversity promotes social exchange and new ideas, but if it is not well understood it can create problems, such as social conflicts and integration issues. Thus, it is important to analyze the effect of cultural aspects on online education in order to understand how MOOCs can be better applied and widespread in a global context.

Several studies point that cultural factors influence teachers 'preferences (Alfy \& Gomes, 2017), students' learning style (Lim, 2004; Heffernan et al, 2010; Krain et al., 2015; Li, 2019), students' performance (Strang, 2010), and the adoption of e-learning and m-learning (Downey et al., 2005, Arpaci, 2015). However, little attention has been given regarding cultural aspects that could influence the MOOCs movement (Liu et al., 2016). Recent literature reviews on MOOCs indicate that cultural issues are one of the least researched and that further analysis is required of questions related to this topic (Bozkurt, Akgun-Ozbek \& ZawackiRichter, 2017; Sanchez-Gordon and Lujan-Mora, 2018; Al-Rahmi et al., 2019). In this context, the current study aims to investigate how cultural aspects influence MOOCs offering.

\section{LITERATURE REVIEW}

The term MOOCs (Massive Open Online Courses) was created to describe online classes designed by higher education institutions aimed at large numbers of participants (Shapiro et al., 2017; Kumar \&A Al-Samarraie, 2018). Renowned universities are offering MOOCs through platforms such as Udacity, Coursera, Edx and others, while technology companies, like Google, are developing their own platforms to assist in the creation and hosting of MOOCs (Pasha, Abidi \& Ali, 2016).

According to Baturay (2015), MOOCs are open, meaning that anyone with access to the Internet can enroll in free open courses, and the content generated through the course is available publicly. Unlike typical higher education programs, MOOCs have no application process and are independent of prior requirements, being also participatory and distributed, which indicates that the participants are encouraged to contribute and share personal contributions (Baturay, 2015; Burd; Smith \& Reisman, 2015).

Openness is as central factor for the development of MOOCs and has the potential to be particularly disruptive for universities (Jacoby, 2014). Regarding the different types of MOOCs, Connectivist MOOCs, also known as cMOOCs, are based on connectivist pedagogical ideas (connection over content) and provide multiple interactions between participants and with network resources, allowing participants to connect and collaborate openly to amplify the content of the courses (Bali et al., 2015; Wang et al., 2017). Extended MOOCs (xMOOCs), on the other hand, present a more institutionalized approach, acting as extensions of university courses (Rhoads, 2015).

A great deal of attention has been given by the literature to the acceptance and use of MOOCs under the perspective of information and communication technologies - ICT, such as the study performed by Khan et al. (2017), which examines the factors that influence the students' adoption of MOOCs in a developing country. The results of the study showed positive effects of task and technology characteristics on behavioral intention. Alraimi, Zo and Ciganek (2015) presented a study that aimed to identify factors that enhance the intention to continue using MOOCs, based on the information systems continuance 
expectation-confirmation model. The research conducted by Wu \& Chen (2017) proposed a unified model integrating the technology acceptance model (TAM), task fit technology (TTF), MOOCs features and social motivation to investigate the continuance intention to use MOOCs.

Other researchers have investigated MOOCs in terms of usability, quality and design (Loizzo \& Ertmer, 2016; Gregori et al., 2018; Kumar \& Al-Samarraie, 2018) as well as the users' responses and behaviors related to the adoption of technology (Chang, Hung \& Lin, 2015; Nordin; Norman, \& Embi, 2015; Liu, Brown \& Lynch, 2016; Joo; So \& Kim, 2018). From the perspective of business and economics, research has also been performed to explore MOOCs business models and their potential to disrupt the higher education sector (Kalman, 2014; Belleflamme \& Jacqmin, 2016).

Regarding cultural aspects, the study of Bozkur and Akbulut (2019) showed that the dropout rates tend to be higher in high cultural contexts than in low culture contexts. Edmundson (2007, p. 99) highlights that "most e-learning courses are designed in Western cultures, whereas the largest and fastest-growing consumer groups live in Eastern cultures, challenging educators to provide e-learning that results in equitable learning outcomes for targeted learners in different cultures".

Several studies emphasize that most of the MOOCs are offered in English and that the dominant ideas from global centers of knowledge located in the United States and England are reflected in the thinking and orientations of most of those designing MOOCs, which makes MOOCs socio-culturally exclusionary for non-English speakers, for those with English as a second language, and for native English speakers in colonized countries (Bozkurt et al., 2018; Altbach, 2014; Adam, 2019; Lambert, 2020). The implications, especially for the developing countries are serious, as agued by Altbach (2014), because MOOCs produced in these centers are easily accessible and inexpensive for the user, but may inhibit the emergence of local academic culture and content focused on the national audience. Thus, despite their potential advantages to local audiences and institutions from developing countries, the number of MOOCs offered in these countries remains low (Pasha, Abidi \& Ali, 2016).

\section{THEORETICAL MODEL AND HYPOTHESIS}

The term culture can be defined as "the collective programming of the mind which distinguishes the members of one group or category of people from another" (Hofstede 2003, p. 861). Hofstede (2003) proposed four dimensions that can be used to predict cross-country differences among national cultures: Individualism as opposed to Collectivism, Masculinity as opposed to Feminility, Uncertainty Avoidance, and Power Distance. In this study we intend to analyze the influence of these four cultural dimensions on MOOCs offering.

\section{Individualism as Opposed to Collectivism}

While members of collectivist cultures value group needs, social norms and cooperation with the group, and are more likely to sacrifice their own interests to achieve group goals, members of highly individualistic cultures believe that the individual is the most important unit (Cox, Lobel \& Mcleod, 1991; Downey et al., 2005). Thus, studies indicate that individualism/collectivism may influence the use of computerbased learning systems (Downey et al., 2005; Balakrishnan, 2017). Keller (2009) points out that in an e-learning context, students from countries with a high degree of individualism are likely to ask questions and contribute more often to online discussions, while students from more collectivist countries tend to not to manifest themselves in the environment of e-learning. According to Alfy and Gomes (2017), in more collectivist societies there is a preference for human interaction over teaching through technologies, which makes instructors feel more comfortable with face-to-face teaching, considering it more effective. Therefore, it is expected that:

H1: There is a positive effect of individualism on MOOCs offering.

\section{Masculinity as Opposed to Feminility}

Masculinity represents societies in which social gender roles are clearly distinct, while femininity represents societies in which these social roles overlap (Hofstede, 2003). Masculine societes are more competitive and 
value achievement, heroism, and material success, while feminine societies are more consensus-oriented and value cooperation, caring for others, and quality of life (Hofstede Insights, 2019). In a context of e-learning implementation, Keller (2009, p. 70) states that "teachers from a masculine culture would expect rewards for developing the use of e-learning tools, while teachers from a more feminine culture would not". In masculine societes, individuals are more likely to adopt technologies if they find them useful in their learning (El-Masri \& Tarhini, 2017). Studies show that women present higher levels of anxiety and more negative perception of technology than men, being less likely to use computers (Zaharias et al., 2007; Harvey et al., 2017). Thus, we hypothesized that:

H2: There is a positive effect of masculinity on MOOCS offering.

\section{Uncertainty Avoidance}

Uncertainty avoidance representes "the degree to which the members of a society feel uncomfortable with uncertainty and ambiguity" (Hofstede, 2003, p. 861). According to Arpaci (2015), individuals from countries with less uncertainty avoidance are more likely to accept and test new products being, therefore, more innovative. Nistor et al. (2013) also state that uncertainty avoidance may have a negative effect on the intention to use technologies. As pointed out by Keller (2009), resistance to the adoption of e-learning is greatest in countries with a high degree of uncertainty avoidance. Thus, we hypothesized the following:

H3: There is a negative effect of uncertainty avoidance on MOOCS offering.

\section{Power Distance}

Power Distance is defined as the degree to which individuals in a society accept the unequal distribution of power in institutions (Hofstede, 2003). Wang (2007) points that the Power Distance dimension of culture may influence online presence and learners' perceptions. Higher perceptions of power distances tend to widen the perceived gulf between students and teachers, resulting in students' reluctance to question and challenge the teacher (Wang, 2007; Hodkinson \& Poropat, 2014). Thus, in the implementation of e-learning systems, Keller (2009) states that countries with a high degree of power distance would implement one-way teaching with teacher-centered education, while in countries with a low degree of power distance, two-way education would be implemented and education would be student-centered. According to the study by Nistor et al. (2013), members of cultures with greater power distances tend to use less educational technologies. Therefore, it is expected that:

H4: There is a negative effect of uncertainty avoidance on MOOCS offering.

The research model with the number of MOOCs offered per country as the dependent variable and four independent variables related to the cultural dimensions of Hofstede (2003) is summarized in Figure 1.

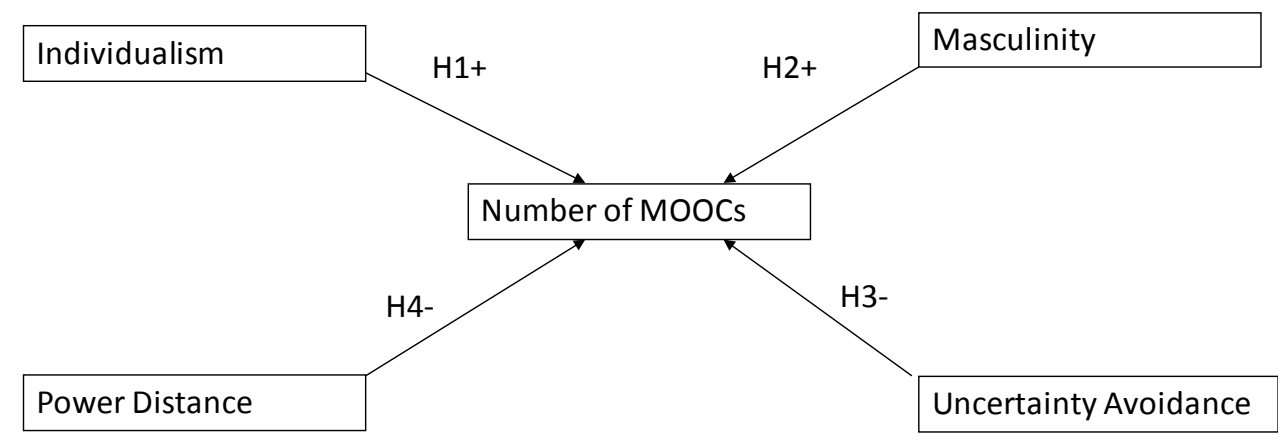

Figure 1. Research Model 


\section{METHOD}

In order to reach the research goal, we first collected data from Class Central (2019), which is a search engine and reviews site where there is a list of online courses offered through Massive Open Online Course (MOOC) platforms. At the Class Central site there was a list of 941 Universities from 55 countries that offer MOOCs. For each university we collected the number of MOOCs and the country where the university is located.

Then, for each country of the sample, we collected four Hofstede's cultural dimensions (Uncertainty avoidance, Power Distance, Masculinity, and Individualism) (Hofstede Insights, 2019). We also collected the population, and percentage of population using the Internet from the World Bank (2019) site.

The data obtained were first analyzed following the descriptive analysis. Through the multivariate regression analysis, we evaluated possible factors related to the number of MOOCs offered in each country. Thus, regression analysis using ordinary least squares was performed with the number of MOOCs offered per country as the dependent variable. In the estimated models, we also observed the variance inflation factor (VIF) statistics that can indicate if the model has any multicollinearity related problem. Four independent variables related to the cultural dimensions of Hofstede (2003) were considered, in line with the four hypotheses previously established in the study. The population, and percentage of population using the Internet were used as control variables.

\section{RESULTS}

First, we analyzed the data collected based on the descriptive statistics. Table 1 displays information related on the variables. Initially, the database had 55 observations. However, after excluding those with missing values for the cultural dimensions and for the control variables, the database reduced to 52 observations. Regarding the individuals using Internet, Nigeria is the country with less percentage of population with access to the Internet (27,681\% of population), followed by El Salvador (31.25\%). The average number of MOOCs offered by country is 187.539 . The maximum number of courses ( 4016 courses) is offered by universities located in the United States, which represents $42 \%$ of the MOOCs. Ukraine, Poland, Nigeria, Kuwait, Greece, El Salvador, and Ecuador have only one course offered by their Universities. These results reinforce those of Edmundson (2007), Pasha et al. (2016), Altbach (2014) and Bozkurt et al. (2018) that pointed to the dominance of institutions from developed and western countries, especially American universities, in the academic thinking and the reflection of this dominance in the development and offering of MOOCs.

Table 1. Descriptive Statistics

\begin{tabular}{lccccc}
\hline Variable & Obs & Mean & Std. Dev. & Min & Max \\
\hline MOOCs & 52 & 187.539 & 569.266 & 1 & 4016 \\
Individualism & 52 & 46.500 & 23.893 & 6 & 91 \\
Masculinity & 52 & 48.519 & 18.355 & 5 & 95 \\
Unc. Avoid. & 52 & 67.154 & 23.831 & 8 & 100 \\
Power Dist. & 52 & 59.038 & 22.320 & 13 & 100 \\
Internet Use & 52 & 75.441 & 18.515 & 27.681 & 98.260 \\
Population (Ln) & 52 & 16.991 & 1.605 & 12.747 & 21.050 \\
\hline
\end{tabular}

After the descriptive analyzes, we performed a bivariate correlation to evaluate possible relationships between the variables considered in the quantitative model. Table 2 shows the correlation matrix. 
Table 2. Correlation Matrix.

\begin{tabular}{|c|c|c|c|c|c|c|c|}
\hline Variables & (1) & (2) & (3) & (4) & (5) & (6) & (7) \\
\hline (1) MOOCs & 1.000 & & & & & & \\
\hline (2) Power Dist. & -0.137 & 1.000 & & & & & \\
\hline (3) Individualism & $0.370 * * *$ & $-0.755 * * *$ & 1.000 & & & & \\
\hline (4) Masculinity & 0.150 & 0.172 & -0.028 & 1.000 & & & \\
\hline (5) Unc. Avoid. & -0.167 & $0.348 * *$ & $-0.378 * * *$ & 0.033 & 1.000 & & \\
\hline (6) Population (Ln) & $0.360 * *$ & $0.315 * *$ & -0.078 & $0.436 * * *$ & 0.050 & 1.000 & \\
\hline (7) Internet Use & 0.016 & $-0.467 * * *$ & $0.480 * * *$ & -0.203 & $-0.263 *$ & $-0.494 * * *$ & 1.000 \\
\hline
\end{tabular}

As the correlation matrix indicated a high correlation between the Individualism and Power Distance variables, and a moderate correlation between Internet Use and Power Distance and between Internet Use and Individualism, before interpreting the results of multivariate regression analysis, we proceeded to the evaluation of the VIF statistics. This evaluation indicates whether there are some concerns related to multicollinearity among the independent variables. However, as can be seen in Table 3, the mean VIF statistic was 1,970 , while the highest value was 2,895 . This result suggests that the quantitative model has no biases resulting from multicollinearity between the explanatory variables.

Table 3. VIF Values

\begin{tabular}{lc}
\hline Variable & VIF \\
\hline Individualism & 2.950 \\
Power Dist. & 2.800 \\
Internet Use & 1.810 \\
Population (Ln) & 1.800 \\
Masculinity & 1.240 \\
Unc. Avoid. & 1.190 \\
\hline Mean VIF & 1.970 \\
\hline
\end{tabular}

Thus, we proceeded to the analysis of the hypotheses based on the results shown in Table 4.

Table 4. Results for the Regression Analysis

\begin{tabular}{lrrrl}
\hline Variable & Coef. & Std. Err. & t & Signif. \\
\hline Individualism & 11.074 & 5.115 & 2.170 & $0.036 * *$ \\
Masculinity & -0.524 & 4.321 & -0.120 & 0.904 \\
Unc. Avoid. & -1.144 & 3.265 & -0.350 & 0.728 \\
Power Dist. & 3.180 & 5.339 & 0.600 & 0.554 \\
Internet Use & 0.637 & 5.170 & 0.120 & 0.903 \\
Population (Ln) & 133.671 & 59.585 & 2.240 & $0.030 * *$ \\
Constant & -2732.170 & 1165.757 & -2.340 & $0.024 * *$ \\
\hline \multicolumn{1}{r}{$\mathrm{n}=$} & 52 & & & \\
$\quad$ Prob $>\mathrm{F}=$ & 3.150 & & & \\
Adj R-squared $=$ & 0.011 & & & \\
\hline
\end{tabular}


The results show that Population presents a significant effect on MOOCs offering, while percentage of population using Internet does not have significant effect. Regarding H1, the results show that Individualism presents a significant and positive effect on MOOCs offering. This result is in line with the study of Alfy and Gomes (2017).

Regarding H2, H3, and H4, Power Distance, Uncertainty Avoidance and Masculinity do not present significant effect on MOOCs offering, which diverges from previous studies (Keller, 2009; Nistor et al., 2013). According to the literature, individuals from countries with higher rates of Masculinity and lower levels of Uncertainty Avoidance and Power Distance are more likely to attend online courses. However, universities in these countries are not necessarily the ones offering more MOOCs.

\section{DISCUSSION AND CONCLUSION}

The objective of this study was to investigate cultural determinants of MOOCs offering. Through a crosscountry analysis, the results show that only the dimension of Individualism has an impact on MOOCs offering. Although the literature indicates that individuals from countries with higher rates of masculinity and lower levels of uncertainty avoidance and power distance are more likely to attend online courses, universities in these countries are not necessarily the ones offering more MOOCs. Thus, universities in countries with higher levels of Masculinity and lower levels of Uncertainty Avoidance and Power Distance could benefit from a potential demand to develop and offer more MOOCs.

The analysis also showed that the number of MOOCs offered in some countries is low, especially in developing countries. The large majority of MOOCs are created and offered by universities from western countries, mainly by those located in the United States. These results reinforce the conclusions of other studies that indicate that most of online courses are offered by universities from developed and western countries.

Although previous studies have indicated that cultural aspects may influence online education, to the best of our knowledge this is the first study that tests the relation between cultural aspects and MOOCs offering. The results of the present study bring some points of reflection. First, if MOOCs have the potential to benefit individuals from developing countries, especially those with no access to formal education, could this potential be fully explored without taking into consideration the cultural values of these countries during the design and implementation of MOOCs? Second, could this gap between cultural dimensions and MOOCs offering, be one of the factors associated to the high dropout rates of these courses?

It is apparent that higher education can benefit from the Massive Open Online Courses, with the expansion of the knowledge to a greater number of learners and the diffusion of these courses worldwide. However, in order to establish the basis for a cross-national education, it is necessary to understand and meet the specific demands of the target audience. By understanding how cultural differences impact on distance education, universities wishing to internationalize their courses will be better able to develop and implement MOOCS that can be accessed by users from different countries.

Future studies can be developed to understand the perception of MOOCs users from eastern countries about the content and pedagogical aspects of the courses offered by universities located in western countries. The perception of individuals from developing countries about the courses offered by institutions from developed countries could also be investigated. 


\section{BIODATA and CONTACT ADDRESSES of AUTHORS}

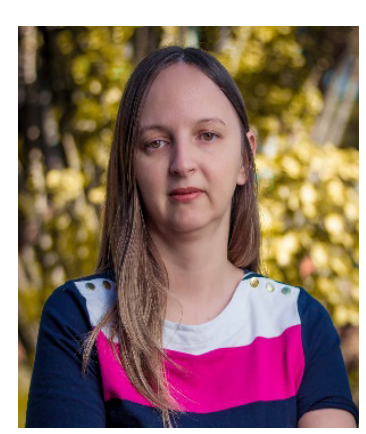

Dr. Fernanda F. O. MALAQUIAS is Full Time Professor at Universidade Federal de Uberlandia, Brazil. In 2012, she received her PhD in Electrical Engineering from Universidade Federal de Uberlandia. She also holds a MS degree in Computer Science. In 2015, she was a Visiting Research Scholar at DePaul University in Chicago, USA. She has published articles in referred journals including Computers in Human Behavior, Electronic Commerce Research and Applications, Information Technology for Development, Technology and Disability, Information Development, Turkish Online Journal of Distance Education, Online Information Review, Energy Research \& Social Science, and Simulation Modelling Practice and Theory.

Fernanda F. O. MALAQUIAS

Faculdade de Gestao e Negocios, Universidade Federal de Uberlandia

Address: Av. Joao Naves de Avila, n. 2121, Bloco F, Sala 1F-216 (FAGEN/UFU)

Uberlandia, Minas Gerais, Brazil.

Phone: +55 (34) 3239-4132,

E-mail: fernandafrancielle@gmail.com

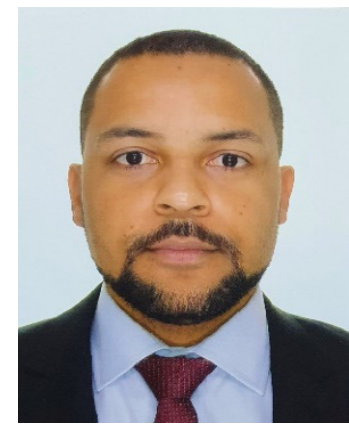

Romes Jorge da Silva JUNIOR received his B.S. degree (2014) and his M.S. degree (2019) in Business Management from Universidade Federal de Uberlandia. Currently, he is a $\mathrm{PhD}$ student at the same institution and works as a chancery officer at the Ministry of Foreign Affairs of Brazil. His most recent research interests include Information Technology users' satisfaction and acceptance.

Romes Jorge da Silva JUNIOR

Faculdade de Gestao e Negocios, Universidade Federal de Uberlandia

Address: Av. Joao Naves de Avila, n. 2121, Bloco F, Sala 1F-216 (FAGEN/UFU)

Uberlandia, Minas Gerais, Brazil.

Phone: +55 (34) 3239-4132,

E-mail: romesjrsilva@yahoo.com.br

\section{REFERENCES}

Adam, A. (2019) Digital neocolonialism and massive open online courses (MOOCs): colonial pasts and neoliberal futures. Learning, Media and Technology, 44(3), 365-380.

Albelbisi, N. A. \& Yusop, F. D. (2019) Factors Influencing Learners' Self-Regulated Learning Skills In A Massive Open Online Course (Mooc) Environment. Turkish Online Journal of Distance Education - TOJDE, 20(3), 1-16.

Alfy, S. E., Gomez, J. M., \& Ivanov, D. (2017). Exploring instructors' technology readiness, attitudes and behavioral intentions towards e-learning technologies in Egypt and United Arab Emirates. Education and Information Technologies, 22(5), 2605-2627.

Al-Rahmi, W., Aldraiweesh, A, Yahaya, N., Kamin, Y. B., \& Zeki, A. M. (2019) Massive Open Online Courses (MOOCs): Data on higher education. Data in Brief, 22, 118-125. 
Alraimi, K. M., Zo, H., \& Ciganek, A. P. (2015). Understanding the MOOCs continuance: The role of openness and reputation. Computers \& Education, 80, 28-38.

Arpaci, I. (2015). A comparative study of the effects of cultural differences on the adoption of mobile learning. British Journal of Educational Technology, 46(4), 699-712.

Altbach, P. G. (2014). MOOCs as neocolonialism: who controls knowledge?. International Higher Education, $75,5-7$.

Balakrishnan, V. (2017). Key determinants for intention to use social media for learning in higher education institutions. Universal Access in the Information Society, 16(2), 289-301.

Bali, M., Crawford, M., Jessen, R., Signorelli, P., \& Zamora, M. (2015). What makes a cMOOC community endure? Multiple participant perspectives from diverse cMOOCs. Educational Media International, 52(2), 100-115.

Baturay, M. H. (2015). An overview of the world of MOOCs. Procedia-Social and Behavioral Sciences, 174, 427-433.

Belleflamme, P., \& Jacqmin, J. (2016). An economic appraisal of MOOC platforms: business models and impacts on higher education. CESifo Economic Studies, 62(1), 148-169.

Bozkurt, A. \& Akbulut, Y. (2019) Dropout Patterns and Cultural Context in Online Networked Learning Spaces. Open Praxis, 11(1), 41-54.

Bozkurt A., Akgun-Ozbek, E. \& Zawacki-Richter, O. (2017) Trends and Patterns in Massive Open Online Courses: Review and Content Analysis of Research on MOOCs (2008-2015). International Review of Research in Open and Distributed Learning, 18(5), 118-147.

Bozkurt, A., Yazici, M. \& Aydin, I. E. (2018) Cultural Diversity and Its Implications in Online Networked Learning Spaces. In: E. Toprak, \& Evrim. G.K., Supporting Multiculturalism in Open and Distance Learning Spaces (p.56-81). Hershey, PA: IGI Global.

Burd, E. L., Smith, S. P., \& Reisman, S. (2015). Exploring business models for MOOCs in higher education. Innovative Higher Education, 40(1), 37-49.

Chang, R. I., Hung, Y. H., \& Lin, C. F. (2015). Survey of learning experiences and influence of learning style preferences on user intentions regarding MOOCs. British Journal of Educational Technology, 46(3), 528-541.

Class Central (2019, Jun 2). List of Universities offering MOOCs. Retrieved from: https://www.classcentral. com/universities

Conole, G. (2015). Designing effective MOOCs. Educational Media International, 52(4), 239-252.

Cox, T. H., Lobel, S. A., \& McLeod, P. L. (1991). Effects of ethnic group cultural differences on cooperative and competitive behavior on a group task. Academy of Management Journal, 34(4), 827-847.

Despujol, I., Castaneda, L., \& Turro, C. (2018). Developing a Mooc Initiative: Lessons Learnt from the Universitat Politecnica de Valencia Experience. Turkish Online Journal of Distance Education TOJDE, 19(1), 215-233.

Downey, S., Wentling, R. M., Wentling, T., \& Wadsworth, A. (2005). The Relationship between National Culture and the Usability of an E-learning System. Human Resource Development International, $8(1), 47-64$.

El-Masri, M., \& Tarhini, A. (2017). Factors affecting the adoption of e-learning systems in Qatar and USA: Extending the Unified Theory of Acceptance and Use of Technology 2 (UTAUT2). Educational Technology Research and Development, 65(3), 743-763.

Edmundson, A. (2007). Using Level 1 e-Learning to Support Socio-Economic Development. Educational Media International, 44(2), 99-111.

Fini, A. (2009). The Technological Dimension of a Massive Open Online Course: The Case of the CCK08 Course Tools. International Review of Research in Open and Distance Learning, 10(5), 1-26. 
Freitas, S. I., Morgan, J., \& Gibson, D. (2015). Will MOOCs transform learning and teaching in higher education? Engagement and course retention in online learning provision. British Journal of Educational Technology, 46(3), 455-471.

Gregori, E. B., Zhang, J., Galvan-Fernandez, C., \& de Asís Fernandez-Navarro, F. (2018). Learner support in MOOCs: Identifying variables linked to completion. Computers \& Education, 122, 153-168.

Harvey, H. L., Parahoo, S., \& Santally, M. (2017). Should gender differences be considered when assessing student satisfaction in the online learning environment for millennials?. Higher Education Quarterly, 71(2), 141-158.

Heffernan, T., Morrison, M., Basu, P. \& Sweeney, A. (2010). Cultural differences, learning styles and transnational education. Journal of Higher Education Policy and Management, 32(1), 27-39.

Hodkinson, C. S., \& Poropat, A. E. (2014). Chinese students' participation: the effect of cultural factors. Education + Training, 56(5), 430-446.

Hofstede, G. (2003). Culture's Consequences: Comparing Values, Behaviors, Institutions, and Organizations across Nations, Behaviour Research and Therapy, 41, pp. 861-862, 2003.

Hofstede Insights (2019, Jun 10). Compare Countries. Retrieved from: https://www.hofstede-insights.com/ product/compare-countries/

Jacoby, J. (2014). The disruptive potential of the Massive Open Online Course: A literature review. Journal of Open, Flexible, and Distance Learning, 18(1), 73-85.

Joo, Y. J., So H. J., \& Kim, N. H. (2018). Examination of relationships among students' self-determination, technology acceptance, satisfaction, and continuance intention to use K-MOOCs. Computers in Human Behavior, 122, 260-272.

Kalman, Y. M. (2014). A race to the bottom: MOOCs and higher education business models. Open Learning: The Journal of Open, Distance and e-Learning, 29(1), 5-14.

Keller, C., Lindh, J., Hrastinski, S., Casanovas, I., \& Fernandez, G. (2009). The impact of national culture on e-learning implementation: a comparative study of an Argentinean and a Swedish university. Educational Media International, 46(1), 67-80.

Khan, I. U., Hameed, Z., Yu, Y., Islam, T., Sheikh, Z., \& Khan, S. U. (2018). Predicting the acceptance of MOOCs in a developing country: Application of task-technology fit model, social motivation, and self-determination theory. Telematics and Informatics, 35(4), 964-978.

Krain, M., Kille, K. J., \& Lantis, J. S. (2015). Active Teaching and Learning in Cross-National Perspective. International Studies Perspectives, 16, 142-155.

Kumar, J. A., \& Al-Samarraie, H. (2018). MOOCs in the Malaysian higher education institutions: The instructors' perspectives. The Reference Librarian, 59(3), 163-177.

Lambert, S. R. (2020) Do MOOCs contribute to student equity and social inclusion? A systematic review 2014-18. Computers \& Education, 145, 1-17.

Li, K. (2019) MOOC learners' demographics, self-regulated learning strategy, perceived learning and satisfaction: A structural equation modeling approach. Computers \& Education, 132, 16-30.

Lim, D. H. (2004). Cross Cultural Differences in Online Learning Motivation. Educational Media International, 41(2), 163-173.

Littlejohn, A., Hood, N., Milligan, C., \& Mustain, P. (2016). Learning in MOOCs: Motivations and selfregulated learning in MOOCs. Internet and Higher Education, 29, 40-48

Liu, Z., Brown, R., Lynch, C., Barnes, T., Baker, R. S., Bergner, Y., \& McNamara, D. S. (2016). MOOC Learner Behaviors by Country and Culture: an Exploratory Analysis. In proceedings of the International Conference on Educational Data Mining, Raleigh, NC, USA, 9, 127-134.

Loizzo, J., \& Ertmer, P. A. (2016). MOOCocracy: the learning culture of massive open online courses. Educational Technology Research and Development, 64(6), 1013-1032. 
Lu, W., Wang, B. \& Lu, Y. (2019). Understanding Key Drivers of Mooc Satisfaction and Continuance Intention to Use. Journal of Electronic Commerce Research, 20(2), 105-117.

Nistor, N., Gogus, A., \& Lerche, T. (2013). Educational technology acceptance across national and professional cultures: a European study. Educational Technology Research and Development, 61(4), 733-749.

Nordin, N., Norman, H., \& Embi, M. A. (2015). Technology Acceptance of Massive Open Online Courses in Malaysia. Malaysian Journal of Distance Education, 17(2), 1-16.

Park Y., Jung, I., \& Reeves, T. C., (2015). Learning from MOOCs: a qualitative case study from the learners' perspectives. Educational Media International, 52(2), 72-87.

Pasha, A., Abidi, S. H., \& Ali, S. (2016). Challenges of offering a MOOC from an LMIC. The International Review of Research in Open and Distributed Learning, 17(6), 221-228.

Rhoads, R. A., Camacho, M. S., Toven-Lindsey, B., \& Lozano, J. B. (2015). The massive open online course movement, xMOOCs, and faculty labor. The Review of Higher Education, 38(3), 397-424.

Sanchez-Gordon, S., \& Lujan-Mora, S. (2018). Research challenges in accessible MOOCs: a systematic literature review 2008-2016. Universal Access in the Information Society, 17(4), 775-789.

Shapiro, H. B., Lee, C. H., Roth, N. E. W., Li, K., Cetinkaya-Rundel, M., \& Canelas, D. A. (2017). Understanding the massive open online course (MOOC) student experience: An examination of attitudes, motivations, and barriers. Computers \& Education, 110, 35-50.

Strang, K. D. (2010). Multicultural e-Education: Student Learning Style, Culture and Performance. In: H. Song, \& T. Kidd (Eds.), Handbook of Research on Human Performance and Instructional Technology (pp. 392-412). Hershey, PA: IGI Global.

Wang, M. (2007). Designing online courses that effectively engage learners from diverse cultural backgrounds. British Journal of Educational Technology, 38(2), 294-311.

Wang, Z., Anderson, T., Chen, L., \& Barbera, E. (2017). Interaction pattern analysis in cMOOCs based on the connectivist interaction and engagement framework. British Journal of Educational Technology, 48(2), 683-699.

World Bank (2019, Sep 3) World Bank Open Data. Retrieved from: https://data.worldbank.org/

Wu, B., \& Chen, X. (2017). Continuance intention to use MOOCs: Integrating the technology acceptance model (TAM) and task technology fit (TTF) model. Computers in Human Behavior, 67, 221-232.

Zaharias, P. (2008). Cross-cultural differences in perceptions of e-learning usability: An empirical investigation. International Journal of Technology and Human Interaction, 4(3), 1-26.

Zawacki-Richter, O., Bozkurt, A., Alturki, U., \& Aldraiweesh, A. (2018). What Research Says About MOOCs - An Explorative Content Analysis. International Review of Research in Open and Distributed Learning. 19(1), 243-259. 